IJTAR

International Journal of Transactional Analysis Research
$3(1), 48-49$

https://doi.org/10.29044/v3i1p48

\title{
Appendix 5: Template of Informed Consent Agreement
}

\author{
(C) 2012 Mark Widdowson
}

The Process and Outcome of Transactional Analysis Psychotherapy in the Treatment of Depression Research

\section{INFORMED CONSENT AGREEMENT}

Please indicate Yes/ No to each item and sign the form in the space provided at the end

I, have received a full description of the purposes and procedures of this research; specifically:

1. I understand what I will be asked to do, as well as the possible risks and benefits of my taking part.

\section{Yes/ No}

2. I voluntarily consent to participate on the basis of the description of the study provided above.

\section{Yes/ No}

3. I realise that, by taking part, I may experience painful emotions or may feel bored or inhibited by the research procedures, and that if I require additional immediate treatment, it might be at my own expense.

\section{Yes/ No}

4. I understand that, if any of these things happen, I can discuss them with my therapist or the principal researcher.

\section{Yes/ No}

5. I understand that the professional researchers managing this project may discontinue my participation at any time if it is not in my best interests or the interests of the research.

\section{Yes/ No}

6. I realise that I may withdraw my consent and participation at any time, without giving a reason and without any of my rights being affected, and also that I can ask to have my data withdrawn from the study at any time, during or after my participation.

\section{Yes/ No}

7. I also understand that I may ask questions about the study at any time before, during, and after it has been conducted.

\section{Yes/ No}


8. I agree that the questionnaire and interview data that I provide for the project can be analysed for the purposes of research, and give permission for these records to be stored so that further study of them can be undertaken.

\section{Yes/ No}

9. I give my permission for my sessions to be recorded for supervision purposes, and that I will later be able to specify the specific research and training uses I will allow to be made of those recordings.

\section{Yes/ No}

10. I understand and agree that data gathered from my sessions will be used to examine trends and themes relating to the sample of clients in this study.

\section{Yes/ No}

11. I understand and agree that an anonymised case study may be written about my therapy and that I will be asked again at the end of my therapy if I am willing for a case study to be written about me and my therapy.

\section{Yes/ No}

12. I understand that all the information I give will be treated with the utmost confidentiality and that my anonymity will be respected at all times. I am aware that I can refrain from answering any question about which I feel uncomfortable.

\section{Yes/ No}

Finally, in signing this agreement, I confirm that:

- I over 18 years of age;

- That I am aware of what my participation involves and any potential risks;

- That all my questions concerning the study have been answered to my satisfaction.

Signed:

Date:

Name:

Research/ Associate:

Signed:

Date: 